\title{
Recent Advances in Tissue Engineering in Prosthodontics and Restorative Dentistry
}

Tissue engineering is a new field of biomedical science which is based on the principles of biology and engineering for the development of functional substitutes for tissues and organs. ${ }^{1}$ The term "tissue engineering" was introduced in medicine in 1987 with a keypoint given by Dr. Joseph Vacanti and Dr. Robert Langer in tissue engineering, describing it as the new technology and referring it as the beginning of new biomedical discipline. ${ }^{2}$ Currently, there is tremendous expansion of tissue engineering in form of cells, scaffolds, growth factors, controlled release carriers, engineering of biomaterials and in other different areas of basic and applied research. ${ }^{3}$

Recent advances in tissue engineering suggest the beginning of significant changes in the traditional areas of clinical dentistry. In the field of restorative

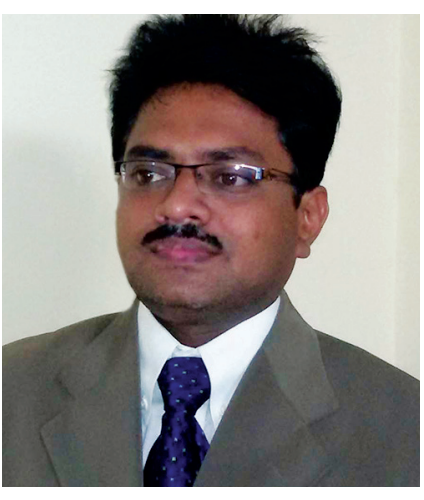
dentistry, Xiao et $\mathrm{al}^{4}$ investigated the effects of combined bioactive multifunctional composite (BMC) and poly (amido amine) (PAMAM) on remineralization of demineralized root dentin in acidic environment and found complete root dentin remineralization in an acidic environment. This method can be promising for $\mathrm{Class} V$ and other restorations for remineralization and protection of tooth structures. Ge et $\mathrm{al}^{5}$ in their study found strong antimicrobial and anticaries properties and biological remineralization capabilities of the adhesive containing PAMAM and dimethylaminododecyl methacrylate (DMADDM). Wu et $\mathrm{al}^{6}$ in their study synthesized a self healing dental luting cement with a microcapsules of poly(urea-formaldehyde) (PUF) shells and triethylene glycol dimethacrylate (TEGDMA). This luting agent promises to heal the cracks and increase the longevity of restoration cemented with this cement. Koto et $\mathrm{al}^{7}$ studied the application of magnetic force to tissue engineering for dental enamel regeneration. A combined cell sheet (CC sheet) consisting of dental epithelial cells (DECs) and dental mesenchymal cells (DMCs) was constructed using magnetic force-based tissue engineering technology. CC sheet employing magnetic nanoparticles (MNPs) could be developed as a novel and unique graft for artificially regenerating dental enamel.

In the field of implant dentistry and prosthodontics many researches were going on in tissue engineering. Arakawa et $\mathrm{al}^{8}$ in their study derived a photocrosslinkable methacrylated glycol chitosan (MeGC) and semiinterpenetrating collagen $(\mathrm{Col})$ composite hydrogels useful in promoting bone regeneration. Ansari et $\mathrm{al}^{9}$ in their review on dental and orofacial mesenchymal stem cells in craniofacial regeneration found that of the available regenerative treatment options, craniofacial tissue regeneration using mesenchymal stem cells (MSCs) shows promising results. Alginate scaffolds encapsulating MSCs can provide a suitable microenvironment for cell viability and differentiation for tissue regeneration applications. Huang et $\mathrm{al}^{10}$ in their study found that zirconia, a biocompatible ceramic commonly used for dental implants, synthesize hollow mesoporous nanocapsules for loading, storage and sustained release of a novel polyamine-stabilized liquid precursor phase of amorphous calcium phosphate (PAH-ACP) for collagen biomineralization and bone marrow stromal cells osteoinduction. Lee et $\mathrm{al}^{11}$ designed a hybrid Titanium (Ti) by modifying Ti surface with heparin loading it with Growth/ differentiation factor-5 (GDF-5). GDF-5 loaded Ti showed significantly enhanced osteogenic differentiation with increased calcium deposition under nontoxic conditions against periodontal ligament stem cells (PDLSc). This hybrid Ti will be useful for remodeling and healing of bone defects for restorative procedures in dentistry.

Recent advances in tissue engineering in field of prosthodontics and restorative dentistry promises significant changes in the more traditional areas of clinical dentistry. It is the prime responsibility of a clinician and academician to update their knowledge in the field of tissue engineering so that better and advanced restorative and implant rehabilitation treatment can be given to patients with long term success.

\section{References}

1. Shah R, ShahH, Shetty O, Mistry G. A novel approach to treat peri implantitis with the help of PRF. Pan African Med J 2017;27:256. 
2. Meyer U. The history of tissue engineering and regenerative medicine in perspective. In: Meyer U, Meyer T, Handschel J, Wiesmann HP, editors. Fundamentals of tissue engineering and regenerative medicine. Springer-Verlag Berlin Heidelberg; 2009. p. 5.

3. Melek LN. Tissue engineering in oral and maxillofacial reconstruction. Tanta Dent J 2015;12: 211- 223.

4. Xiao S, Liang K, Weir MD, Cheng L, Liu H, Zhou X, et al. Combining bioactive multifunctional dental composite with PAMAM for root dentin remineralization. Materials (Basel) 2017; 22;10(1):E89.

5. Ge Y, Ren B, Zhou X, Xu HHK, Wang S, Li M, et al. Novel dental adhesive with biofilm-regulating and remineralization capabilities. Materials (Basel). 2017;10(1): E26.

6. Wu J, Zhang Q, Weir MD, Oates TW, Zhou C, Chang X, et al. Novel self-healing dental luting cements with microcapsules for indirect restorations. J Dent 2017 ;66:76-82.

7. Koto W, Shinohara Y, Kitamura K, Wachi T, Makihira S, Koyano K. Porcine dental epithelial cells differentiated in a cell sheet constructed by magnetic nanotechnology. Nanomaterials (Basel) 2017;7(10):E322.

8. Arakawa C, Ng R, Tan S, Kim S, Wu B, Lee M. Photopolymerizable chitosan-collagen hydrogels for bone tissue engineering. J Tissue Eng Regen Med 2017 ;11(1):164-174.

9. Ansari S, Seagroves JT, Chen C, Shah K, Aghaloo T, Wu BM, et al. Dental and orofacial mesenchymal stem cells in craniofacial regeneration: The prosthodontist's point of view. J Prosthet Dent 2017;118(4):455-461.

10. Huang XQ, Yang HY, Luo T, Huang C, Tay FR, Niu LN. Hollow mesoporous zirconia delivery system for biomineralization precursors. Acta Biomater. 2017 Dec 2. pii: S1742-7061(17)30746-8. doi: 10.1016/j.actbio.2017.11.049. [Epub ahead of print]

11. Lee SJ, Bae MS, Lee DW, Heo DN, Lee D, Heo M. The use of heparin chemistry to improve dental osteogenesis associated with implants. Carbohydr Polym 2017 ; 157 : 1750-1758.

Sunil Kumar Mishra

Managing Editor

International Journal of Prosthodontics and Restorative Dentistry

Professor, Department of Maxillofacial Prosthodontics and Implantology Peoples College of Dental Sciences \& Research Centre,

Bhopal, Madhya Pradesh, India e-mail: sunilmsr200@yahoo.co.in 